\title{
The Effect of Cognitive Dissonance on External Information Search and Consumer Complaint Responses
}

\author{
Banu Külter Demirgüneş ${ }^{1} \&$ Mutlu Yüksel Avcilar ${ }^{2}$ \\ ${ }^{1}$ Department of Business Administration, Ahi Evran University, Kırşehir, Turkey \\ ${ }^{2}$ Department of Management Information Systems, Osmaniye Korkut Ata University, Osmaniye, Turkey \\ Correspondence: Banu Külter Demirgüneş, Department of Business Administration, Ahi Evran University, Kırşehir, \\ Turkey.
}

Received: February 10, 2017

Accepted: March 6, 2017

Online Published: March 10, 2017

doi:10.5430/ijba.v8n2p57

URL: https://doi.org/10.5430/ijba.v8n2p57

\begin{abstract}
The cost of influencing a new customer rapidly increases and exceeds the cost of retaining existing customer. Thus, companies tend to be more concerned with customer retention. Keeping their current market share is one of the important tasks for companies. Understanding why customers complain and switch from one company to another help companies to retain their customers. One of the reasons consumers engage in negative responses can result from dissonance experienced after purchase. The concept cognitive dissonance has been studied widely in the literature of consumer behavior. However, there are few studies discussing the relation between cognitive dissonance (its dimensions) and consumers' complaint responses. This study adopts the 22-item scale of Sweeney et al. (2000) in order to evaluate consumers' level of cognitive dissonance after purchasing a smartphone.

This study offers three dimensions of cognitive dissonance -emotion, wisdom of purchase and concern over deal- as the predictors of external information search and consumer complaint responses. This study tests whether cognitive dissonance has significant effects on consumers' search for external information, and in turn, on consumers' complaint and switching intention. The empirical analysis was carried out based on the data gathered by 400 smartphone users, living in Ankara, the capital city of Turkey. The survey result was analyzed by using Partial Least Squares (PLS-PM) analysis method. The results reveal that when consumers feel emotional and rational inconsistencies after smartphone purchasing, they need information from external sources (such as asking friends, relatives, other stores), and this information search behavior leads to negative consumer responses as complaint and switching intention.
\end{abstract}

Keywords: cognitive dissonance, external information search, complaint intention, switching intention

\section{Introduction}

Cognitive dissonance is identified as paradoxical feeling in a person's mind or uncomfortable state arising when a person has two conflicting feeling simultaneously (Liu and Keng, 2014, p. 980). When a person has this kind of thought, he experiences a gap between positive expectations and negative results. Many researchers, especially in the psychology field (Murray et al. 2012), have offered that cognitive dissonance emerges in all type of personalities, but the degree can be different (Liu and Keng, 2014, p. 982). The initial argument in the literature has treated cognitive dissonance as a post-purchase phenomenon. Until recently, some researchers (Koller and Salzberger, (2007) indicated that phenomenon could occur as a pre-purchase situation. Koller and Salzberger (2007) studied the effects of cognitive dissonance prior to decision making after the decision. They stated that dissonance reduction strategies should be considered and evaluated at all stages of purchase process (Yap and Gaur, 2014, p. 119).

Cognitive dissonance is a temporary condition. It refers to a strong motivation to get over the unpleasant state. Thus, a high level of cognitive dissonance is generally followed by activities of people so as to decrease cognitive dissonance (Salzberger and Koller, 2010, p. 6). According to the theory of cognitive dissonance, inconsistencies that individual felt result in psychological discomfort and this will prompt consumers to eliminate or reduce cognitive dissonance (Yap and Gaur, 2014, p. 117). When such a feeling occurs, people search for different ways to diminish the stress. One of the ways for reducing the stress after buying a product is to communicate about the conflicting experience. The other way can be seeking for more information. Milliman and Decker (1990) indicate that 
consumers may reduce cognitive dissonance by getting more information. By acquiring more information, they can increase their trust towards the purchased product (Liu and Keng, 2014, p. 982). Consumers' response to this tension and dissonance reduction strategies that they adopt to decrease the tension has been important for marketing practice (Yap and Gaur, 2014, p. 117).

One of the ways that consumers adopt to decrease the tension is to engage in negative responses such as complaint and switching. Complaints are usually evaluated as negative responses from dissatisfied people and companies should try to avoid them. However, negative responses may be useful for companies as important markers of strategy to be followed (Rizwan et al., 2013, p. 89). Actually, complaints can help companies to become in aware of troubles and take action. Many researchers (Fernandes and Santos, 2008; Rizwan et al., 2013) explored the relation between dissatisfaction and complaint intention. Yet, there are limited studies discussing the concept of cognitive dissonance -a negative response but different from dissatisfaction- and its dimensions on consumer's response, in terms of a complaint and switching intention (Rizwan et al., 2013, p. 89). Actually, the studies about cognitive dissonance (as an empirical study) are still scarce (Salzberger and Koller, 2010, p. 6).

Researchers have given important attention to the drivers and consequences of post-purchase complaint intentions of consumers and their behaviors. However, the cognitive dissonance concept and its emotional and rational dimensions have not received much attention to evaluat with complaint responses (CREs) of a consumer. The current study fills this gap by focusing on the relation between dissonance and complaint responses.

Consumers can engage in different and various CREs (e.g., complaint intention, switching intention and negative word of mouth) (Singh, 1988, p. 93). Consumer complaint behavior can be identified as "a set of behavioral and nonbehavioral responses which are perceived as a disappointment after purchase (Singh, 1988) (Rizwan et al., 2013, p. 91). Consumer complaint intention is treated as an attitudinal perspective of a consumer rather than complain behavior. In this study, complaint intention is defined as "the plan of an unhappy consumer to communicate a complaint to the company", similar to the study of Rizwan et al., (2013).

Switching intention can also be evaluated as a strategy to decrease potential dissonance (Salzberger and Koller, 2010). Exploring customer switching has also gained important attention recently, even though customer switching mechanisms are not completely understood (Shin and Kim, 2008, p. 879) Setiawan and Haryanto (2014) indicate that company can use customers' intention to switch for maintaining its relationship with customers. In this study customer switching intention defines the "willingness of a customer to give up their current smartphone product in favor of other smartphone product". That is, the concept refers to product switching intention.

When consumers are dissonant, they look for support for their beliefs and they want to confirm that selected product is better than alternatives. If consumers show inconsistency between attitude and post-purchase behavior (e.g., they can feel regret about purchase decision they made), they tend to seek for information from external sources (e.g., television, newspaper, magazines, Internet, friends, other stores) to be sure that they make the right decision (Keng and Liao, 2009, p. 1337). Thus, external information search can be another tension reduction strategy after purchasing.

The marketing literature about consumer CREs has mainly based on defining various drivers of CREs, including attitude toward complaining (Singh and Wilkes, 1996), perceived cost (Richins, 1980), controllability (Folkes, 1984), knowledge precedent (Day, 1984) and demographic and environmental variables (Singh and Wilkes, 1996). Most literature based on identifying drivers of CREs. The role of emotional or rational variables has not been the main point in explaining CREs. There are only a few studies considering "cognitive dissonance" concept with CREs. This study aims to feel this gap. Thus, the main contribution of the current study is to extend the cognitive dissonance application to smartphone purchasing by examining its role on consumer's external information search and CREs.

The study empirically tests the proposed model by using data that is gained from smartphone users. That is, the study investigates the effect of cognitive dissonance on external information search and intention to complain and switch in the smartphone market. The reason for choosing smartphone product is that it is a durable product and requires some effort for choosing and prices for most people are perceived as relatively high. Electronic products are categorized as complex goods because their level of technology is high and they are classified as multi-functional goods. A consumer is likely to think about its features, negative and positive sides of the product about its defectiveness, performance etc. (Ors et al., 2015, p. 280). The investigated sector is also important to make a clear identification. One of the main features of the telecommunication sector is that it is complicated and technological advancement is high. Thus, unpredictable technology environment makes it important to better define consumer's intention (Shin and Kim, 2008, p. 879). Thus, one of the main contributions of this study is its providing insights for understanding complaint and switching intention in the smartphone market. It will be especially important when the high level of 
competition in the mobile market is considered (Shin and Kim, 2008, p. 36). From the point of practical marketing implication, the current study provides a perspective to smartphone marketers for designing suitable strategy that can diminish negative intentions of consumers. Companies can take actions to dissonance reduction strategies (Setiawan and Haryanto, 2014, p. 134).

Thus, the main question in this study is to test how likely consumers experienced cognitive dissonance is to engage in external information search, switching and complaint intentions. The study develops a set of hypotheses describing how cognitive dissonance dimensions influence these constructs. This study examines some relevant questions in the field of cognitive dissonance: 1) the relationship between dimensions of cognitive dissonance and external information search 2) the impact of external information search on complaint intention, and 3) the impact of external information search on switching intention.

The next section discusses the definitions of cognitive dissonance, external information search, complaint intention and switching intention. With this background, the current study offers a path model in which three dimensions of cognitive dissonance influence consumer's external search for information about purchased product, which in turn affect CREs (complaint intention and switching intention). Then research method is defined and the relationships in the model are tested. Finally, this study discusses empirical results and offers directions for future researches.

\section{Theoretical Background and Hypothesis Development}

\subsection{Cognitive Dissonance}

Cognitive dissonance is described as a psychologically uncomfortable situation motivating a person to reduce (Festinger, 1957). A person being in a dissonant state is described as a person whose feelings, behaviors and desires are inconsistent. For some people, cognitive dissonance is an intolerable and painful thing (Festinger, 1957: 266; Sweeney et al., 2000, p. 373). Cooper and Fazio (1984) considered the concept as an inconsistency and expectation resulting in undesirable consequences. The concept of cognitive dissonance includes unknown outcomes. That is, why it is described as psychologically uncomfortable state and psychological discomfort (Menasco and Hawkins, 1978; Elliot and Devine, 1994).

Cooper and Fazio (1984) differentiated between two psychological components as "dissonance as a psychologically uncomfortable state" and "dissonance arousal". Arousal is defined as a necessary condition for dissonance to occur. When dissonance occurs, this discomfort motivates dissonance reduction, as complied with dissonance theory. As described by most researchers, cognitive dissonance is generated by inconsistent cognitions and it includes both emotional and cognitive components (Sweeney et al., 2000, p. 374).

Dissonance is not aroused or emerged in every purchase. There are three main conditions for the arousal of it (Oliver, 1997). Firstly, a consumer must give value to the decision. That means the consumer has spent an important amount of money and a psychological cost for the decision. The outcome of the decision must be a matter to the consumer. Secondly, the consumer must consider himself as free to make the choice. Thirdly, the consumer must show irrevocable commitment to the decision once made. That means the decision must be irreversible. Especially, decisions that include long-term outcomes are more likely to create dissonance results (Sweeney et al., 2000, p. 374).

After a decision, people usually experience a discomfort mental state referred to cognitive dissonance (Sweeney et al., 2000, p. 374). Cognitive dissonance has mostly been treated as synonymous with post-purchase anxiety, related to important purchase involving evaluation of attractive alternatives. For instance, a consumer who bought an expensive car can experience dissonance. A consumer may have a thought about the purchase and consider another alternative might have been a better choice. Post-purchase dissonance is a result of evaluations of what could have been and if the decision of purchase had been made differently. Consequently, cognitive elements conflict in the consumer's mind. As it leads to discomfort, it brings a strong force to eliminate the disagreeable condition. As a result, cognitive dissonance presumes a series of attitudinal and behavioral changes that aim at reaching a more consistent system of cognitions (Koller and Salzberger, 2012, p. 262).

Many researchers (Menasco and Hawkins, 1978; Elliot and Devine, 1994) have measured cognitive dissonance with different items or with one or more indicators. Montgomery and Barnes (1993) and Sweeney et al., (2000) developed a dissonance scale to use in marketing. Direct measures of dissonance arousal have concentrated mostly on physiological responses. Montgomery and Barnes (1993) offered a scale of cognitive dissonance that defines the main of cognitive dissonance as "those feelings, emotions, and attitudes which consumers have when they experience dissonance and the situation has occurred (Montgomery and Barnes, 1993: 206). Sweeney et al., (2000) offered a multi-dimensional instrument consisting of an emotional dimension, a dimension referred to as wisdom of purchase and a dimension concerning the deal. 
Many of the emotional items representing the emotional aspect of dissonance refer to a negative end of the pleasure dimensions such as angry, frustrated, annoyed and depressed. Some items represent the higher end of arousal dimensions such as angry, excited and annoyed. Besides, cognitive items refer to the feelings about the wisdom of purchase decision that took place. They are related to the self-attribution. For example, "I wondered if I could have made a better purchase. I thought I should not have done it." This dimension of cognitive dissonance is linked with "whether the choice was right and whether I really needed that product". Lastly, concern over deal is mostly related to the salesperson (Sweeney et al., 2000, p. 376).

Emotional dimension is defined as the psychological discomfort of a person following the purchase decision. Wisdom of purchase is defined as a person's feeling after the purchase that may not have needed the selected product and the selected one may not be a suitable one. Concern over deal is defined as the recognition of a person after the purchase that he may have affected against his own beliefs by sales staff (Sweeney et al., 2000, p. 380).

Many researchers offered that there are emotional and cognitive aspects of cognitive dissonance (Montgomery and Barnes, 1993; Sweeney et al., 2000; Koller and Salzberger, 2012). Cognitive aspect is defined as the recognition of a person whose beliefs are inconsistent after the purchase whereas emotional aspect is defined as the psychological discomfort of a person, subsequent to a purchase decision. This study used a scale that can be used to measure emotional and cognitive aspects of dissonance in the post-purchases by adopting Sweeney et al., (2000)'s measurement scale. Sweeney et al., (2000) offered the 22-item scale used to measure cognitive dissonance. The scale includes three dimensions; emotional dimension, a dimension referred to as wisdom of purchase and a dimension as concern over deal. In this study, the validity of the scale is also tested by assessing its relationship with other related constructs, such as external information search, complaint intention, and switching intention.

Salzberger and Koller (2010) indicate that dissonance contributes to a complaint behavior. Post-purchase consumers who are dissatisfied involve in different behaviors, such as a complaint to the company, negative word of mouth, appeal to a third party, and external information search (Kim, 2011; Leonidou and Skarmeas, 2015). Sweeney et al., (2000) found that emotional aspect of dissonance is closely related to consumers' difficulty in judging the quality of the product. Concern over deal is also found a great impact on perceived value and satisfaction (Sweeney et al., 2000, p. 380).

Thus, the expectation of this study is that consumers having high dissonance level will have much more effort to search for external information about the product bought and this will result in high level of complaint intention and switching intention.

\subsection{External Information Search}

External information search is defined as "the degree of perception, attention, and effort that is devoted to obtain information about specific purchases" (Beatty and Smith, 1987). It is not surprising that consumers want to be informed for decision making (Leonidou and Skarmeas, 2015). Kelley (1973) states that people use information about distinctiveness and consistency of a behavior in order to make causal judgments about behavior. Consumers who are dissonant about the purchased product seek additional external information sources for confirming or disconfirming their dissonance or doubts. Especially in the new product development, consumer's doubt and hesitation about new product cause additional information search. Besides, more additional information may be required for the new technology based products, like smartphones.

Information seeking represents consumers' tendency to search for additional information that is related to purchasing. Consumers can need information not only before purchasing but also after purchasing and using (Leonidou and Skarmeas, 2015). Previous research indicates that lack of trust and ambiguity cause a tendency to search for information (Sinecaur, 2010). Thus, information seeking is mostly related to doubts and dissonance in that answers can be gathered if knowledge, evidence, and information are available. Consumers' skepticism about their post-purchase can need information to correct the purchase and want to relieve. Thus, dissonant consumers are more likely to search for information about the product purchased. They want to know if they have made the right choice and what is wrong and they need for information about other product brands or competitors' products. They ask friends, access discussion groups, websites, read ingredient details and read certification to enrich understanding of features of the product, help check products claims and reduce perceived risk related to the performance of purchased product (Leonidou and Skarmeas, 2015). Wang (2010) also indicates that emotional and rational factors have an importantly significant influence on information search.

Thus, this study discusses that three dimensions of cognitive dissonance would influence external information search positively and offers the following hypotheses: 
Hypothesis (H1): Emotional discomfort is positively related to external information search.

Hypothesis (H2): Wisdom of purchase is positively related to external information search.

Hypothesis (H3): Concern over deal is positively related to external information search.

Accordingly, this study proposes that consumers engage in external information search after experiencing dissonance, and then external information search may affect consumers' complaint responses such as complaint and switching intention.

Thus, this study argues that external information search would cause complaint intention and switching intention and offers the following hypotheses:

Hypothesis (H4): External information search is positively related to consumer complaint intention.

Hypothesis (H5): External information search is positively related to switching intention.

\subsection{Complaint Intention}

The phenomenon of consumer complaint behavior (CCB) is believed to be started with some emotions or feelings of perceived dissatisfaction (Day, 1984; Singh, 1988). According to Zeelenberg and Pieters (1999) switching and complaining to a company and engaging in negative word of mouth communication are the main types of complaint behavior. The responses of consumer complaint are believed to fit into two categories, as behavioral and nonbehavioral. Behavioral responses have been the main point of studies of complaint behavior. These responses are not limited to direct actions toward the seller (i.e., retailer, manufacturer etc.). Behaviors also include third parties such as legal actions or even relatives and friends (e.g., negative word of mouth). These responses are evaluated in the behavioral responses category (Richins, 1983; Day, 1984). Besides, some people can choose nonbehavioral responses in relatively similar dissatisfying episodes. Nonbehavioral responses seem to be not only justified but also need to understand the process that underlies the complaint responses (Singh, 1988, p. 94).

Day (1984) offered that the aim of complaining can be used to categorize behavioral CCB into three actions. 1) Redress seeking; consumer tries to seek remedy directly or indirectly from the seller (e.g., take legal actions, complain to manufacturer etc.) 2) Complaining; the motivation is to communicate dissatisfaction other than seeking remedy (e.g., to persuade relatives, friends by word of mouth to affect future behavior) 3) Personal boycott; the motivation is to give purchasing of the offending service (involving product, store/manufacturer or brand) (Singh, 1988, p. 95).

CCB is generally treated as disconfirmation paradigm (Butelli, 2007). If the experience exceeds the expectations, positive disconfirmation occurs and the customer is satisfied. On the contrary, if the expectations are not satisfied by the experience, negative disconfirmation occurs and the customer is dissatisfied. Dissatisfaction should be evaluated as an antecedent of complaining. Day (1984) indicates that complaining behavior is following to dissatisfaction and is a set of activities influenced by personal and situational factors.

Complaining is not a cost-free action. Companies should understand that consumers give time to communicate complaints and spend psychological effort, including fear, embarrassment, incertitude etc. (Butelli, 2007). By complaining, customers can seek for various outcomes. For example, they wait for a tangible solution, through the exchange, refund, and repair. On the other hand, they can wait for a psychological compensation including a social benefit "avoiding dissatisfaction before occurring to others or including apologies" (Landon, 1977, p. 32). Companies should not ignore the importance of defining and responding to consumer complaints. Kim et al., (2003) indicate that 10 to 15 percent of a company's sales loss can be caused by dissatisfied consumers (Kim et al., 2003, p. $352)$.

Dissatisfaction contributes to complaining intentions (Rizwan et al., 2013, p. 93). The concept of "complaint responses" or "complaint behavior" implies all plausible reactions to dissatisfaction (Day, 1984; Fernandes and Santos, 2008). Singh (1988) indicates that CCB utilizes the variety of responses which can be categorized into three dimensions; complaint to the seller, switch company and negative word of mouth. Svari and Olsen (2012) indicate that when a negative experience is attributed to the company, causing irritation, anger, frustration that are characterized as external emotions, customers are likely to complain directly to the company. However, if customers attribute the responsibility to themselves, emotions that are more internal such as fear, guilt and shame and they tend to use indirect soft of complaint behaviors (for example, the use of social media and blogs to complain). This study focuses on consumers' complaint intention directly to the company (Svari and Olsen, 2012, p. 273). Thus, complaint intention is defined as consumer's intention of directly complaining to the company. Consumers' direct complaining 
provides the company with a great chance to improve the situation and get back its customer. Then the customer justifies the encouragement of the company (Jin, 2010, p. 89).

Heung and Lam (2003) indicate that only a small percentage of customers who experience negative conditions prefer to complain directly to the company. The majority of them choose after actions such as switching to other companies or negative word of mouth. The reason for this can be found in emotions of customers (Zeelenberg and Pieters, 1999). However, few studies exist on how differently emotional and rational feelings lead to different complaint behaviors. Following the idea that different emotions can cause different complaining behavior, this study offers emotional and cognitive constructs can also cause different outcomes (Svari and Olsen, 2012, p. 270). Besides, many researchers found a positive and direct relationship between complaining behavior and dissatisfaction (Fernandes and Santos, 2008, p. 585). By focusing on different concept, this study proposes that cognitive dissonance will positively impact complaint and switching intentions.

\subsection{Switching Intention}

Switching intention is one of the types of consumer complaint responses (Zeelenberg and Pieters, 1999) Setiawan and Haryanto (2014, p. 127) define switching intention as "the willingness of a customer to give up their current product, brand or supplier". They define the intention to switch smartphone as "a customer's migration value from their old feature phone to new feature one even from existing brand to another brand". According to Keaveney and Parthasarathy (2001), switching is a concept that denotes an action by a customer due to the increased competition among brands. In this study, customer switching intention refers to product switching intention which indicates the willingness of a customer to give up his current smartphone product, even from existing brand to another.

Han et al., (2011) indicate that switching intention, customer retention, repurchase intention, and customer loyalty are all related. Whereas retention, repurchase intention and loyalty represent favorable outcome for the company, switching intention presents unfavorable outcomes. Keaveney (1995) dictates that "behavioral intention" involves both rebuy intention and switching intention. Behavioral intention is defined as "stated likelihood to engage in a behavior" (Oliver, 1997, p. 28). Switching intention identifies negative consequences for a company. The term refers to the probability of exchanging the current brand/company with another (Han et al., 2011, p. 621).

Since long-term customer relationships are crucial, companies should not only try to manage customer satisfaction but they should also manage the switching behavior. However, customers do not always actually switch product or brand because of switching barriers such as strong interpersonal relationship, high switching cost (perceptions of customers on money), time and effort related to changing supplier and alternatives' attractiveness that refer to if a more suitable alternative exists (Julander and Söderlund, 2003, p. 4). There are a set of factors which consisting such barriers; transaction costs, search costs, loyal customer discounts, emotional cost, social risk etc. When consumers' intent to switch, they will think how good other suppliers are and compare them with current supplier. Thus, companies can effectively engage in interpersonal relations and try to make the product more attractive among alternatives. They should increase the likelihood of continued relationship (Julander and Söderlund, 2003, p. 6). Mohsan et al., (2011) indicate that $70 \%$ of customers switching their providers or current products tell that they were satisfied with their previous providers or products. However, they changed their service providers due to price, or the competitors are providing new opportunities. So many researchers offer marketers to predict customers' future needs and providing before anyone else (Mohsan, 2011, p. 266).

Some factors contribute to switching intention of a customer such as dissatisfaction (Crosby and Stephen, 1987), perceptions of quality (Rust and Zahorik, 1993), satisfaction (Bitner, 1990). The decline in satisfaction may also cause an increase in perceptions of switching benefits. Dissatisfied consumers perceive substantial benefits to switching and they will be more likely to switch than satisfied customers (Jones et al., 2000, p. 263). Ross (1999) indicates that emotions can also play an important role at the moment of the switching decision. They found that positive emotions in a supermarket are not strong when the focus is on switching behavior. Alternatively, a customer can react with strong emotions in bad situations (Ross, 1999, p. 80). Although a problem occurs and causes switching intention, it does not always mean that this will be customer's final decision to switch the brand or company (Clemes, et al., 2007, p. 51). However, many researchers (Setiawan and Haryanto, 2014) indicate that there is a close relation between switching behavior and switching intention. Keaveney (1995) finds additional studies necessary to diminish the probability of switching and to avoid it before actually switching.

Based on the above literature review, the current study tests a theoretical model that shows dissonant consumer's response after purchasing a smartphone. The responses are evaluated in terms of external information search, complaint intention, and switching intention. The model specifies a causal relationship between dimensions of 
cognitive dissonance and external information, and in turn, the relation with CREs as complaint and switching intention. The research model is presented in the Figure 1 given below.

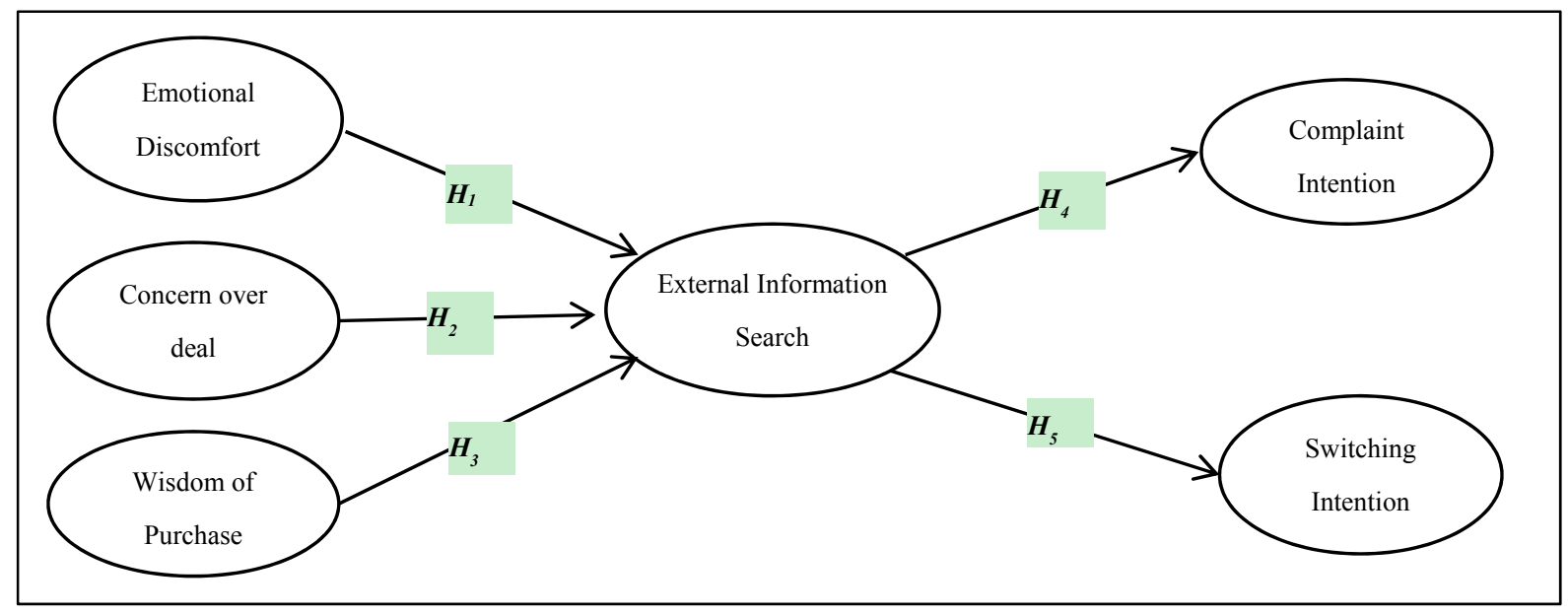

Figure 1. Research Model

\section{Research Method}

\subsection{Data Collection and Sample}

The empirical analysis of this study was performed based on the data obtained from smartphone users, living in Ankara, the capital city of Turkey. The survey was performed in Kizılay, one of the frequent roads in the city. Face to face survey method was used in order to obtain the data. The sample includes 400 customers who have bought their smartphones not more than 3 months ago. That means respondents were selected among smartphone users who have recently purchased. The reason for this is that cognitive dissonance is a temporary condition and intensity of dissonance level may decrease after a long (Salzberger and Koller, 2010, p. 6). Respondents were also selected among smartphone users having bought their smartphones from offline electronics retailers because concern over deal dimension includes meeting with sales staff at the purchasing stage. Therefore, purposive sampling technique, a non-probability sampling method, was used in order to meet these preconditions.

The data was collected during two months in August and September 2016. Respondents were asked to evaluate their purchasing of current smartphones. They were wanted to share their dissonant experiences after purchasing. Then, the respondents rated their dissonance levels about purchasing, their tendency to search for external information, and their intention to complain towards the retailer and intention to switch the product.

\subsection{Measures and Variables}

This study used the 22-item measurement scale of Sweeney et al., (2000) to measure cognitive dissonance. Original measurement scale includes three dimensions of cognitive dissonance as emotion, wisdom of purchase and concern over deal. Questionnaire items were measured by a five-point Likert scale from 1 to 5, rating from strongly disagreement to strongly agreement. Fifteen items were used to measure the emotional component of dissonance. Wisdom of purchase is captured by four items, whereas concern over deal dimension is captured by three items. The indicators of all components contain negative feelings after the purchase. Emotional components include items referring to feelings such as angry, depression, annoying, etc. The items of wisdom of purchase indicate the judgments whether the product is the right choice and whether the other alternatives are better. The items of concern over deal indicate the judgment whether the buyer is cheated at the purchasing stage.

This study also offered other three constructs as external information search, complaint intention, and switching intention. Measurement of consumer's external information search includes four items adopted from Keng and Liao (2009). Consumer's complaint intention directly towards the company was measured by using three items adopted from Singh (1988) and Rizwan et al., (2013). The questionnaire items for switching intentions were adopted from Julander and Söderlund (2003) and Zhang et al., (2012). These items were also measured by a five-point Likert scale. The items used to measure the constructs are shown in Table 1. 
Table 1. Measurement of constructs

\begin{tabular}{|c|c|}
\hline Constructs & Items \\
\hline $\begin{array}{l}\text { Emotional } \\
\text { Discomfort }\end{array}$ & $\begin{array}{l}\text { I felt disappointed with myself. } \\
\text { I was in despair. } \\
\text { I felt annoyed. } \\
\text { I felt depressed. } \\
\text { I felt angry. } \\
\text { I was in pain. } \\
\text { I felt frustrated. } \\
\text { I resented it. } \\
\text { I felt scared. } \\
\text { I felt I'd let myself down. } \\
\text { I felt furious with myself. } \\
\text { I felt uneasy. } \\
\text { I felt hollow. } \\
\text { I felt sick. } \\
\text { I was in agony. }\end{array}$ \\
\hline Wisdom of Purchase & $\begin{array}{l}\text { I wonder If I really need this product. } \\
\text { I wonder If I have made the right choice. } \\
\text { I wonder If I have made the right thing in buying this product. } \\
\text { I wonder whether I should have bought anything at all. }\end{array}$ \\
\hline Concern Over Deal & $\begin{array}{l}\text { After I bought this product, I wondered If I had been fooled. } \\
\text { After I bought this product, I wondered If they had spun me a line. } \\
\text { After I bought this product, I wondered whether there was something wrong with the } \\
\text { deal I got. }\end{array}$ \\
\hline $\begin{array}{l}\text { External Information } \\
\text { Search }\end{array}$ & $\begin{array}{l}\text { After I bought this product, I asked the comments of my relatives, neighbors or friends } \\
\text { about the product. } \\
\text { After I bought this product, I searched for information about the product through stores } \\
\text { and manufacturers. } \\
\text { After I bought this product, I searched for information about the product on the internet. } \\
\text { After I bought this product, I searched for information about the product on TV, radio, in } \\
\text { magazines, newspapers or reports. }\end{array}$ \\
\hline Complaint Intention & $\begin{array}{l}\text { I absolutely ask the company for the problem on the product. } \\
\text { I do not easily forget unpleasant problems without complaining or protesting. } \\
\text { If I experience a problem with the product, I will go back or call the company and ask } \\
\text { them to take care of my problem. }\end{array}$ \\
\hline Switching Intention & $\begin{array}{l}\text { I am considering to switch from my current product. } \\
\text { I am determined to change my current product with another product. } \\
\text { The likelihood of me switching to another product is high. } \\
\text { I am considering whether another product can hold the place of current product. }\end{array}$ \\
\hline
\end{tabular}

\subsection{Data Analysis}

Structural equation modeling with partial least squares (PLS-SEM) method was used to determine the validity and reliability of the measurement model and to test the hypotheses in the research model. PLS-SEM is a component-based structural equation modeling method to test theoretical relations between latent variables (Garson, 2016: 8). PLS-SEM is offered in an early stage of theoretical development so as to test and validate exploratory models (Henseler at al. 2009). PLS-SEM uses observed data for estimating path coefficients in the research model by aiming to minimize the explained variance of target endogenous construct. Thus, PLS-SEM is variance-based 
approach to structural equation modeling (Hair, et al., 2017: 14). PLS-SEM enables researchers to assess simultaneously both measurement model and structural model. PLS-SEM relies on ordinary least squares estimation to solve the models, thereby relaxing the assumption of multivariate normality (Hair et al. 2017). In addition, PLS-SEM can easily handle reflective and formative measurement models, as well as single-item constructs, with no identification problems (Henseler et al. 2009; Hair et al. 2017). Despite the stated advantages, PLS-SEM method is criticized mainly on five issues in the literature. These criticisms are (1) the technique cannot be applied when structural models contain circular relationships between the latent variables, (2) producing biased parameter estimates, (3) not correcting for endogeneity problem, (4) not accommodating measurement error, (5) lack of model overidentification tests (Hair et al. 2017; Rönkkö et al., 2015; McIntosh et al., 2014). Considering benefits and drawbacks of the PLS-SEM method, we used this technique to test research hypotheses. The analysis was performed via SmartPLS 3 (v.3.2.6) software (Ringle et al. 2015).

\section{Results}

\subsection{Demographic Profiles of the Respondents}

The 400 valid questionnaires were collected from the respondents. The demographic profile of the respondents is presented in Table 2. Almost half of the participants consisted of male $(51 \%)$ and the others were female $(49 \%)$. More than half of the respondents (56\%) were married and almost two-thirds of the respondents $(60 \%)$ explained their age as 26-41. Among participants of the survey, nearly $37 \%$ of them indicated that they had completed undergraduate level of education. In terms of occupation, $23 \%$ of the respondents reported their occupation as a tradesman; nearly $19 \%$ of the respondents reported their occupation as a government official, $18 \%$ of the respondents reported their occupation as a self-employed, and $12 \%$ of the respondents indicated their occupation as a worker. More than two-third of the respondents (65\%) reported their average monthly income level between 3,001-7,000 Turkish liras. 34\% of the respondents indicated that they have been using Samsung smartphones, while 31\% of respondents stated that they have been using IPhones. In addition, nearly $25 \%$ of those surveyed stated that they have been using their smartphones for less than one month, $40 \%$ of those participants indicated that they have been using their smartphones for two months and $35 \%$ of the participants indicated this time as for three months. Furthermore, $56 \%$ of the respondents indicated that they used the android, $31 \%$ of them used IOS and $13 \%$ of them used the windows operating system. Moreover, $30 \%$ of the respondents stated that the smartphone price level was between 2,000-2,999 TL and 57\% of the respondents indicated that screen size of their smartphone was 4.8-5.7 inch. Finally, when the smartphone's internal storage space is asked, nearly $40 \%$ of respondents indicated the internal storage capacity of their smartphones as $32-64 \mathrm{~GB}, 31 \%$ of the respondents stated as $4-16 \mathrm{~GB}$, and $30 \%$ of the respondents indicated the internal storage space of their smartphones as $128 \mathrm{~GB}$ and over.

Table 2. Demographic profiles of the sample $(\mathrm{N}=400)$

\begin{tabular}{|c|c|c|c|c|c|}
\hline Gender & Frequency & Percentage & Using Smartphone brand & Frequency & Percentage \\
\hline Male & 205 & 51 & Samsung & 136 & 34.0 \\
\hline Female & 195 & 49 & Apple iPhone & 124 & 31.0 \\
\hline Age & Frequency & Percentage & Asus & 39 & 9.8 \\
\hline$\overline{18-25}$ & 110 & 27.5 & LG & 27 & 6.8 \\
\hline $26-33$ & 131 & 32.7 & General Mobile & 22 & 5.5 \\
\hline $34-41$ & 102 & 25.5 & Lenovo & 18 & 4.5 \\
\hline $42-49$ & 34 & 8.5 & HTC & 16 & 4.0 \\
\hline 50 and over & 23 & 5.8 & HUAWEI & 11 & 2.8 \\
\hline Marital Status & Frequency & Percentage & Others & 7 & 1.8 \\
\hline Married & 222 & 55.5 & Smartphone purchased time & Frequency & Percentage \\
\hline Single & 178 & 44.5 & Less than one month & 99 & 24.7 \\
\hline Educational Level & Frequency & Percentage & 2 months & 163 & 40.8 \\
\hline Elementary education & 34 & 8.5 & 3 months & 138 & 34.5 \\
\hline Secondary education & 45 & 11.3 & Smartphone operating system & Frequency & Percentage \\
\hline Vocational school & 147 & 28.5 & Android & 225 & 56.2 \\
\hline
\end{tabular}




\begin{tabular}{lcclcc} 
Undergraduate & 208 & 36.8 & IOS & 124 & 31.0 \\
Postgraduate & 42 & 10.5 & Windows & 51 & 12.8 \\
\hline Occupation & Frequency & Percentage & The price level of smartphone & Frequency & Percentage \\
\hline Government official & 77 & 19.3 & Under 1,000 TL & 73 & 18.2 \\
Worker & 47 & 11.8 & $1,001-1,999 \mathrm{TL}$ & 110 & 27.5 \\
Self-employed & 71 & 17.8 & $2.000-2,999 \mathrm{TL}$ & 119 & 29.8 \\
Tradesman & 93 & 23.3 & 3,000 TL and over & 98 & 24.5 \\
Student & 33 & 8.3 & Screen size of the smartphone & Frequency & Percentage \\
Housewife & 46 & 11.5 & $2.8-4.7$ inch & 101 & 25.3 \\
Retired & 24 & 6.0 & $4.8-5.7$ inch & 229 & 57.2 \\
Other & 9 & 2.3 & 5.8 inch and over & 70 & 17.5 \\
\hline Monthly Average Income & Frequency & Percentage & Smartphone's internal storage space & Frequency & Percentage \\
\hline Under 1,000 TL & 40 & 10.0 & $4-16$ GB & 124 & 31.0 \\
1,001-3,000 TL & 68 & 17.0 & $32-64$ GB & 158 & 39.5 \\
3,001- 5,000 TL & 233 & 58.3 & 128 GB and over & 118 & 29.5 \\
5,001-7,000 TL & 28 & 7.0 & & & \\
7,001-9,000 TL & 18 & 4.5 & & &
\end{tabular}

\subsection{Measurement Model Validation}

PLS-SEM analysis process is carried out in two stages. In the first stage of the analysis process, the validity and reliability analyses of the measurement model are performed. After the adequacy of the psychometric properties of the reflective measurement model has been established, it is passed to the second step and the coefficients of the structural model are interpreted. Reliability, discriminant and convergent validity and average variance extracted (AVE) indices are calculated for the measurement models. The following section reports the results and key statistics for each of these two stages.

During the measurement model assessment, firstly, reliability is evaluated by the criterion, Cronbach's $\alpha$ larger than 0.70 . Convergent validity is evaluated by three criteria: Firstly, item loadings $(\lambda)$ are larger than 0.70 and statistically significant. Secondly, composite construct reliability is larger than 0.80 and thirdly, average variance extracted (AVE) is larger than 0.50 (Fornell and Lacker, 1981; Chin, 1998; Hair et al., 2017). Then discriminant validity is evaluated. The square root of AVE for each latent construct is larger than its correlations with all other latent constructs (Fornell and Lacker, 1981). The results of convergent validity are presented in Table 3.

Table 3. Convergent validity

\begin{tabular}{lccccccc}
\hline Reflective Constructs & Items & Mean & SD & $\begin{array}{c}\text { Item } \\
\text { Loadings * }\end{array}$ & AVE & $\begin{array}{c}\text { Cronbach's } \\
\text { Alpha }\end{array}$ & $\begin{array}{c}\text { Remposite } \\
\text { Reliability }\end{array}$ \\
\hline \hline Emotional Discomfort & 15 & 3.669 & 0.625 & $0.787-0.850$ & 0.767 & 0.885 & 0.913 \\
Concern Over Deal & 3 & 3.826 & 0.846 & $0.852-0.900$ & 0.769 & 0.851 & 0.909 \\
Wisdom of Purchase & 4 & 3.227 & 0.940 & $0.743-0.897$ & 0.684 & 0.872 & 0.904 \\
External Information Search & 4 & 3.521 & 0.864 & $0.753-0.886$ & 0.792 & 0.875 & 0.914 \\
Complaint Intention & 3 & 3.559 & 0.916 & $0.826-0.942$ & 0.814 & 0.908 & 0.930 \\
Switching Intention & 4 & 3.153 & 0.957 & $0.879-0.933$ & 0.845 & 0.910 & 0.943 \\
\hline
\end{tabular}

*Factor loadings of reflective measurement model are statistically significant at $(p<0.001)$; Diagonal elements (values in parentheses) are the square root of the AVE and the off-diagonal values show the correlations between the latent constructs. 
As indicated in Table 3 , standardized item loadings are statistically significant $(\mathrm{p}<0.001)$ on their respective construct and range from 0.743 to 0.942 . Cronbach's $\alpha$ coefficients range from 0.851 to 0.910 , and all are above the recommended level of 0.70. Analysis result indicates that all reflective constructs have high-level internal consistency. Composite construct reliabilities range from 0.904 to 0.943 , and all are above the recommended level of 0.80 . Average variance extracted (AVE) values range from 0.684 to 0.845 and all are above the minimum recommended level of 0.50 . This indicates the convergent validity for all constructs.

Table 4. Discriminant validity

\begin{tabular}{lcccccc}
\hline Constructs & ED & COD & WP & EIS & CI & SI \\
\hline \hline Emotional Discomfort & $\mathbf{( 0 . 8 7 6 )}$ & & & & & \\
Concern Over Deal & 0.305 & $\mathbf{( 0 . 8 7 7 )}$ & & & & \\
Wisdom of Purchase & 0.327 & 0.593 & $\mathbf{( 0 . 8 2 7 )}$ & & & \\
External Information Search & 0.239 & 0.564 & 0.394 & $\mathbf{( 0 . 8 9 0 )}$ & & \\
Complaint Intention & 0.213 & 0.630 & 0.532 & 0.430 & $\mathbf{( 0 . 9 0 2 )}$ & \\
Switching Intention & 0.352 & 0.278 & 0.306 & 0.224 & 0.156 & $\mathbf{( 0 . 9 1 9 )}$ \\
\hline
\end{tabular}

Note: Diagonal elements (values in parentheses) are the square root of the AVE; the off-diagonal values present the correlations between the latent constructs. Emotional Discomfort (ED), Concern over deal (COD), Wisdom of Purchase (WP), External Information Search (EIS), Complaint Intention (CI), and Switching Intention (SI).

Table 4 shows the results of discriminant validity. Diagonal elements (values in parentheses) present the square root of the AVE, whereas the off-diagonal values are the correlations between the latent constructs. Results of analysis reveal that the square root of the AVE for each construct is larger than its correlations with all other constructs. The analysis result supports the discriminant validity of reflective measurement. Therefore, analysis results present an acceptable level of reliability, convergent and discriminant validity. Analysis results show that our data and measurement model are suitable for assessment of structural model and hypothesis testing process.

\subsection{Structural Model Testing}

Structural path coefficients' statistical significance levels were estimated by means of bootstrapping routine (5.000 subsample and 400 bootstrap cases). Stone-Geisser's $Q^{2}$ values were also obtained via the blindfolding procedure so as to assess the predictive relevance of the models. Table 5 shows the results of the structural relationship of path coefficients, standard deviations for path coefficients, t-statistic values, p-values, and hypothesis test results.

Table 5. PLS-PM structural model analysis results

\begin{tabular}{|c|c|c|c|c|c|c|c|}
\hline $\begin{array}{l}\text { Hypothesized Relations } \\
\text { Between Constructs }\end{array}$ & $\begin{array}{c}\text { Path } \\
\text { Coefficient }\end{array}$ & SD & $\begin{array}{c}\mathrm{t}- \\
\text { Statistic* }\end{array}$ & $\begin{array}{c}\mathrm{p}- \\
\text { Value }\end{array}$ & Hypothesis & $\begin{array}{l}\text { Proposed } \\
\text { Effect } \\
\text { Sign }\end{array}$ & Decision \\
\hline $\begin{array}{l}\text { Emotional Discomfort-> External } \\
\text { Information Search }\end{array}$ & 0.122 & 0.041 & $2.975 * *$ & 0.0029 & $\mathrm{H}_{1}$ & + & Supported \\
\hline $\begin{array}{l}\text { Concern over Deal-> External } \\
\text { Information Search }\end{array}$ & 0.339 & 0.036 & $9.416^{* *}$ & 0.000 & $\mathrm{H}_{2}$ & + & Supported \\
\hline $\begin{array}{l}\text { Wisdom of Purchase-> External } \\
\text { Information Search }\end{array}$ & 0.106 & 0.045 & $2.355^{*}$ & 0.0185 & $\mathrm{H}_{3}$ & + & Supported \\
\hline $\begin{array}{l}\text { External Information Search-> } \\
\text { Complaint Intention }\end{array}$ & 0.264 & 0.046 & $5.757 * *$ & 0.000 & $\mathrm{H}_{4}$ & + & Supported \\
\hline $\begin{array}{l}\text { External Information Search-> } \\
\text { Switching Intention }\end{array}$ & 0.206 & 0.058 & $3.566^{* *}$ & 0.000 & $\mathrm{H}_{5}$ & + & Supported \\
\hline
\end{tabular}

Note: * t- statistic values for two-tailed test: 1.96 (Sig. Level 5\%), and 2.58 (Sig. Level 1\%). 
PLS-SEM analysis result (in Table 5) indicates that emotional discomfort dimension significantly and positively affects external information search $(\beta=.122 ; \mathrm{SD}=.041 ; \mathrm{p}<0.01)$. This result statistically supports Hypothesis 1 , indicating a person's psychological discomfort, subsequent to the purchase of a smartphone, is positively related to external information search behavior. Therefore, there is evidence that a higher-level of psychological discomfort can lead to higher-level external information search behavior. In addition, concern over deal dimension has a positive and significant influence on external information search $(\beta=.339 ; \mathrm{SD}=.036 ; \mathrm{p}<0.01)$. This result empirically supports Hypothesis 2, indicating that a person's recognition after the purchase is influenced by sales staff and this is positively related to external information search behavior. That is, a higher-level of concern over deal perception can cause a higher-level external information search behavior. Besides, wisdom of purchase dimension affects external information search dimension positively and significantly $(\beta=.106 ; \mathrm{SD}=.045 ; \mathrm{p}<0.05)$. This result empirically supports Hypothesis 3. According to PLS-PM analysis results, three dimensions of cognitive dissonance affect the external information search significantly and positively. When relative effects are considered, the effect of the concern over deal on external information search is higher than other two dimensions' effects. In addition, PLS-PM analysis result reveals that the structural path linking external information search and complaint intention is found positive and statistically significant $(\beta=.264 ; \mathrm{SD}=.046 ; \mathrm{p}<0.01)$. This result empirically supports Hypothesis 4 , indicating the positive effect of external information search on complaint intention. Thus, the result shows that a higher-level of external information search causes more complaint intention. Lastly, PLS-SEM analysis result indicates that the level of external information search has a positive and significant effect on switching intention $(\beta=.206 ; \mathrm{SD}=.058 ; \mathrm{p}<0.001)$, supporting Hypothesis 5 . That means the consumer searching for external information is more likely to switch his current smartphone. When relative effects are considered, the influence of the external information search on complaint intention is higher than its effect on switching intention.

Finally, PLS-SEM blindfolding procedure was performed to examine the predictive accuracy and relevance of the structural model, as shown in Table 6.

Table 6. PLS results for endogenous latent construct predictive accuracy and relevance

\begin{tabular}{lccc}
\hline Endogenous Latent Constructs & $\mathrm{R}^{2}$ & $\mathrm{Q}^{2}$ & Effect Size* $^{*}$ \\
\hline \hline External Information Search & 0.369 & 0.248 & Medium \\
Complaint Intention & 0.343 & 0.232 & Medium \\
Switching Intention & 0.317 & 0.181 & Medium \\
\hline Assessing predictive relevance $\left(\mathrm{Q}^{2}\right)$ value of the effect size: $0.02=$ Small, $0.15=$ Medium, $0.35=$ Large.
\end{tabular}

As seen in Table 6, the $\mathrm{R}^{2}$ values for external information search, complaint intention, and switching intention were calculated as $0.369,0.343$, and 0.317 respectively. In addition, Stone-Geisser's $Q^{2}$ values for external information search, complaint intention, and switching intention were calculated as $0.248,0.232$, and 0.181 respectively. Therefore, PLS-PM analysis results reveal that the research model fits the data well.

\section{Conclusion}

This study predicts the effect of consumers' cognitive dissonance level on their external information search and complaint responses, in the context of smartphone purchasing. A consumer's post-purchase dissonance is evaluated with the constructs of external information search, complaint intention, and switching intention. Three dimensions of cognitive dissonance (emotional discomfort, concern over deal and wisdom of purchase) are estimated to be the antecedents of these constructs. The study results in the acceptance of all hypotheses in the research model.

Firstly, concern over deal dimension of cognitive dissonance has a statistically significant and positive effect on consumer's search for external information. That is, when the level of concern over deal increases, the consumer will be more likely to search for external information. Concern over deal dimension is closely related to a salesperson. A consumer who feels discomfort with concern over deal will probably think that salesperson cheated him and there was something wrong with the deal. A consumer thinks that salesperson told him a line during purchasing. This study reveals that such a discomfort state has the strongest effect on consumer's searching for information. This result is partially similar to the study of Sweeney et al., (2000). The current study offers the significant effect of concern over deal on information search, whereas Sweeney et al., (2000) offer its positive impact on satisfaction and perceived value, as a positive outcome. Thus, it is advisable for smartphone sellers to effectively manage their sales staff. Sales people should take good care of customers during the purchasing process. They should provide customers 
with necessary and correct information about the product. They should give time for customers to think so that the customers can feel less tension about the deal and need require less external information. Deceptive sales techniques should be avoided in order to reduce consumers' post-purchase dissonance.

The result of this study supports the positive effect of emotional discomfort on external information search. That means emotional discomfort dimension cause consumers' asking friends, relatives about their current smartphones. The more a consumer feels psychologically discomfort after the purchase, the more he wants to reduce this tension. Thus, following to purchase a smartphone, a consumer can feel negative pleasures, such as depressed, annoyed, angry and frustrated. As a result, these feelings lead to more need for information. This result supports the study of Sweney et al., (2000), indicating that emotional aspect of dissonance is related to difficulty in evaluating the products' quality. Thus, it is natural for a consumer to require additional information, when they are dissatisfied or dissonant. Previous studies have mainly focused on emotions' positive effects like satisfaction (Brown and Kirmani, 1999) and loyalty (DeWitt et al., 2008). However, this study presents a negative outcome as external information search after the purchase. Actually, companies should evaluate consumers' need for external information as a negative outcome. Because this study reveals that dissonant consumer needs additional information and this indicates there is something wrong with the purchase. The need for tension reduction emerges as information search as a negative reaction. Thus, smartphone sellers should provide adequate information at all stages of purchasing, not only before purchasing but also after purchasing. Providing information after purchasing and offering after-sales services prevent consumer to search for information through other stores.

The other dimension of cognitive dissonance, wisdom of purchase, is also found to have a significant and positive effect on external information search. Wisdom of purchase is treated as a rational component of cognitive dissonance. This study reveals that when a consumer is doubtful about the rightness of the choice, he may also require external information. He may not be sure that the selected product is really needed and think the product is not suitable for him. All these beliefs lead to information search because consumer expects additional information to reduce rational discomfort. Thus, smartphone sellers should also convince customers that they have made the right choice. For instance, they may dictate the strong aspects of the product.

In summary, both cognitive and emotional dimensions cause consumers to search for external information. That is, a higher-level of rational and emotional discomfort cause a higher-level of external information search behavior. When relative effects are considered, the effect of the concern over deal, indicating doubts and skeptic feelings with the deal and sales staff, has the strongest effect on external information search.

The research model finally confirms that consumers' external information search has a statistically significant and positive effect on both complaint intention and switching intention. This result indicates that information need for confirming or disconfirming doubts result in negative responses as complaint and switching intention. This result is also consistent with the studies of (Keng and Liao, 2009), indicating the effect external information search on complaint intention. When the external information sources increase and consumers ask for these sources, they will be more likely to intend to complain and consider taking direct action towards the seller. They will probably search for remedy directly from the seller. This can be evaluated as a reaction to dissonance. Thus, companies should decrease the attractiveness of other information sources by providing required and adequate information. This is especially true for new technology based products like smartphones. In addition, it is so easy for consumers to access infinite information sources because of today's internet technology.

The result of the study also shows that a higher-level of external information search causes more willingness to give up the current smartphone. Increased competition among these kinds of technologically based products and brands is better to express the importance of the subject. As the level of information search increases, consumer thinks more about other products/brands and compares their current products with other alternatives. As Crosby and Stephen (1987) indicates that dissatisfaction causes switching. Thus, it is advisable for smartphone sellers to reduce the probability of switching. One way to avoid switching is to develop continued relationship as a switching barrier. Previous research offers a close relation between switching intention and switching behavior (Crosby and Stephen, 1987). Thus, it should be avoided before actually switching. Thus, smartphone sellers are advised to develop trust and long-term relationships with their customers. One way to avoid customer's switching is to strength personal relations between employees and customers. Besides, they should adequately respond the complaint.

Empirical findings of this study give practical implications for smartphone sellers. They can consider the reasons causing customers to complain and switch their smartphones, in the context of cognitive dissonance. If they know the background of consumers' negative responses, they can develop strategies to maintain customer retention. 
This study is limited with the dissonance that consumers experience after smartphone purchasing. The model of the research can be checked for other products that are perceived riskier by consumers (i.e., more expensive and durable products such as furniture, automobile). Because the effectiveness level of the dimensions of dissonance can change and lead to different behavioral intentions. Although post-purchase dissonance is frequently related to more expensive products, Koller and Salzberger (2012) studied on products that have less financial losses and have comparatively small expenditures. Thus, future studies can also compare these two types of purchases, in the context of cognitive dissonance.

One limitation of this study is that it focuses on the traditional retail channel. That means it focuses on the dissonance of consumers purchasing their smartphones from offline electronic stores. This may be a shortcoming, because, in the case of electronic product purchases, emotional and rational components can result in different responses.

This study also focuses on two outcomes as complaint intention and switching intention. However, consumer complaint response includes one more outcome as negative word of mouth communication (Zeelenberg and Pieters, 1999; Svari and Olsen, 2012). Customers may express their negative experiences and feelings both on traditionally as face to face or they can express their feelings on online platforms. This complaint response can also be evaluated in future studies.

\section{References}

Beatty, S.E., \& Smith, S.M. (1987). External search effort: An investigation across several product categories. Journal of Consumer Research, 14(1), 83-95. https://doi.org/10.1086/209095

Bitner, M. (1990). Evaluating Service Encounters: The effects of physical surroundings and employee responses. Journal of Marketing, 54(2), 69-82. https://doi.org/10.2307/1251871

Brown, T. J., \& Kirmani, A. (1999). The influence of pre-encounter effects on satisfaction with anxiety- provoking service encounter. Journal of Service Research, 1(4), 333-346. https://doi.org/10.1177/109467059914005

Butelli, S. (2007). Consumer complaint behavior (CCB): A literature review. In Newcastle: Northumbria University, 2007.

Chin, W.W. (1998). The partial least squares approach to structural equation modeling. Modern Methods for Business Research, 295(2), 295-336.

Clemes, M.D., Gan, C., \& Zheng, L. (2007). Customer switching behavior in the New Zealand banking industry. Banks and Bank Systems, 2(4), 50-65.

Cooper, J., \& Fazio, R.H. (1984). A new look at dissonance theory. In L. Berkowitz (Ed.), Advances in experimental social psychology (Vol. 17, 229-266). San Diego, CA: Academic Press. https://doi.org/10.1016/s0065-2601(08)60121-5

Crosby, L.A., \& Stephens, N. (1987). Effects of relationship marketing on satisfaction, retention and prices in the life insurance industry. Journal of Marketing Research, 24, 404-411. https://doi.org/10.2307/3151388

Day, R.L. (1984). Modeling choices among alternative responses to dissatisfaction, Advances in Consumer Research, Ann Arbor, MI, 496-499.

DeWitt, T., Nguyen, D.T., \& Marshell, R. (2008). Exploring customer loyalty following service recovery: The mediating effects of trust and emotions. Journal of Service Research, 10(3), 269-281.

Elliot, A.J., \& Devine, P.G. (1994). On the motivational nature of cognitive dissonance: Dissonance as psychological discomfort. Journal of Personality and Social Psychology, 67, 382-394. https://doi.org/10.1037/0022-3514.67.3.382

Fernandes, D.H., \& Santos, C. P. (2008). The Antecedents of Consumer Complaining Behavior (CCB). Advances in Consumer Research, 35, 584-592.

Festinger, L. (1957). A theory of cognitive dissonance. Stanford. CA: Stanford University Press.

Folkes, V.S. (1984). Consumer reactions to product failure: An attributional approach. Journal of Consumer Research, 10, 398-409. https://doi.org/10.1086/208978

Fornell C., \& Larcker, D.F. (1981). Evaluating structural equation models with unobservable variables and measurement error. Journal of Marketing Research, 18(1), 39-50. https://doi.org/10.2307/3151312

Garson, G. D. (2016). Partial Least Squares Regression and Structural Equation Models. 2016 Edition (Statistical Associates Blue Book Series 10), Statistical Associates Publishing, USA. 
Hair Jr, J. F., Hult, G.T.M., Ringle, C., \& Sarstedt, M. (2017). A primer on partial least squares structural equation modeling (PLS-SEM). (2nd ed.) Sage Publications.

Han, H., Kim, W., \& Hyun, S.S. (2011). Switching intention model development: Role of service performances, customer satisfaction and switching barriers in the hotel industry. International Journal of Hospitality Management, 30, 619-629. https://doi.org/10.1016/j.ijhm.2010.11.006

Henseler, J., Ringle, C.M., \& Sinkovics, R.R. (2009). The use of partial least squares path modeling in international marketing. Advances in International Marketing, (20), 277-320.

Heung, V.C.S., \& Lam, T. (2003). Customer complaint behavior towards hotel restaurant services. International Journal of Contemporary Hospitality Management, $\quad$ 15(5), 283-289. https://doi.org/10.1108/09596110310482209

Jin, L. (2010). Determinants of customers' complaint intention: an empirical study in the context of China's retail industry. Nankai Business Review, 1(1), 87-99. https://doi.org/10.1108/20408741011032872

Jones, M., David, A., Mothersbaugh, L., \& Beatty, S. E. (2000). Switching barriers and repurchase intentions in services. Journal of Retailing, 76(2), 259-274. https://doi.org/10.1016/S0022-4359(00)00024-5

Julander, C.R., \& Söderlund, M. (2003). Effects of switching barriers of satisfaction, repurchase intentions, and attitudinal loyalty. SSE/EFI Working Paper Series in Business Administration, No.2003.1. Stockholm: January 2003.

Keaveney, S.M. (1995). Customer switching behavior in service industries: An exploratory study. Journal of Marketing, 59, 71-82. https://doi.org/10.2307/1252074

Keaveney, S.M., \& Parthasarathy, M. (2001). Customer switching behavior in online services: An exploratory study of the role selected attitudinal, behavioral and demographic factors. Journal of Academy of Marketing Science, 29(4), 374-390. https://doi.org/10.1177/03079450094225

Kelley, H.H. (1973). The processes of causal attribution. American Psychologist, 28(2), 107-128.

Keng, C.J., \& Liao, T.H. (2009). Consequences of post purchase dissonance: The mediating role of an external information search. Social Behavior and Personality, 37(10), 1327-1340.

Kim, C., Kim, S., Im, S., \& Shin, C. (2003). The effect of attitude and perception on consumer complaint intentions. Journal of Consumer Marketing, 20(4), 352-371. https://doi.org/10.1108/07363760310483702

Kim, Y.S. (2011). Application of cognitive dissonance theory to the service industry. Services Marketing Quarterly, 32, 96-112. https://doi.org/10.1080/15332969.2011.557602

Koller, M., \& Salzberger, T. (2007). Cognitive dissonance as a relevant construct throughout the decision-making and consumption process-An empirical investigation related to a package tour. Journal of Customer Behavior, 6 , 217-227. https://doi.org/10.1362/147539207X251022

Koller, M., \& Salzberger, T. (2012). Heterogeneous development of cognitive dissonance over time and its effect on satisfaction and loyalty. Journal of Customer Behavior, 11(3), 261-280.

Landon, E. L. (1977). A model of consumer complaint behavior. Consumer Satisfaction, Dissatisfaction, and Complaining Behavior, Day, R. (Ed.), India, 31-35.

Leonidou, C.N., \& Skarmeas, D. (2015). Gray shades of green: Causes and consequences of green skepticism. Journal of Business Ethics, 26 August. https://doi.org/10.1007/s10551-015-2829-4

Liu, Y., \& Keng, C.J. (2014). Cognitive dissonance, social comparison and disseminating untruthful or negative truthful e-wom messages. Social Behavior and Personality, 42(6), 979-994.

McIntosh, C.N., Edwards, J.R., \& Antonakis, J. (2014). Reflections on Partial Least Squares Path Modeling. Organizational Research Methods, 17(2), 210-251. https://doi.org/10.1177/1094428114529165

Menasco, M.B., \& Hawkins, D.I. (1978). A field test of the relationship between cognitive dissonance and state anxiety. Journal of Marketing Research, 15, 650-655. https://doi.org/10.2307/3150639

Milliman, R.E., \& Decker, P. (1990). The use of post-purchase communication to reduce dissonance and improve direct marketing effectiveness. Journal of Business Communication, 27, 159-170. 
Mohsan, F., Nawaz, M.M., Khan, M.S., Shaukat, Z., \& Aslam, N. (2011). Impact of customer satisfaction on customer loyalty and intentions to switch: Evidence from banking sector of Pakistan. International Journal of Business and Social Science, 2(16). 263-270.

Montgomery, C., \& Barnes, J.H. (1993). POSTDIS: A short rating scale for measuring post purchase dissonance. Journal of Consumer Satisfaction, Dissatisfaction and Complaining Behavior, 6, 204-216.

Murray, A.A., Wood, J.M., \& Lilienfeld, S.O. (2012). Psychopathic personality traits and cognitive dissonance: Individual differences in attitude change. Journal of Research in Personality, 46, 525-536.

Oliver, R.L. (1997). Satisfaction: A behavioral perspective on the consumer. McGraw-Hill, New York.

Ors, H., Yllmaz, V., \& Sen, R. (2015). A structural equation model for the description and comparison of complaint behavior after purchasing electronic, food and textile products. Journal of Business, Economics and Finance, 4(2), 268-288.

Richins, M.L. (1980). Consumer perceptions of costs and benefits associated with complaining. In Hunt, H.K and Day, R.L. (Eds.), Refining concepts and measures of consumer satisfaction and complaining behavior (pp.50-53). Indiana University Press, Bloomington, IN.

Ringle, C.M., Wende, S., \& Becker, J.M. (2015). SmartPLS 3. Boenningstedt: SmartPLS GmbH.

Rizwan, M., Behzad, M., Ali, M., Khan, M.W., \& Khan, M. (2013). Determinants of customer complain intention: A study from Pakistan. International Journal of Learning Development, 3(6), 88-105.

Rönkkö, M., McIntosh, C.N., \& Antonakis, J. (2015). On the adoption of partial least squares in psychological research: Caveat emptor. Personality and Individual Differences, 87, 76-84.

Ross, I. (1999). Switching Processes in Customer Relationships. Journal of Service Research, 2(1), 68-85.

Rust, R.T., \& Zahorik, A.J. (1993). Customer satisfaction, customer retention and market share. Journal of Retailing, 69, 193-215. https://doi.org/10.1016/0022-4359(93)90003-2

Salzberger, T., \& Koller, M. (2010). Investigating the impact of cognitive dissonance and customer satisfaction on loyalty and complaint behavior, Revista Brasileira de Marketing, 9(1), 5-16.

Setiawan, M.M., \& Haryanto, B. (2014). The antecedent variables of attitude in forming intention to switch smartphone. European Journal of Business and Social Sciences, 3(6), 126-135.

Shin, D.H., \& Kim, W.Y. (2008). Forecasting customer switching intention in mobile service: An exploratory study of predictive factors in mobile number portability. Technological Forecasting and Social Change, 75, 854-874.

Sinaceur, M. (2010). Suspending judgment to create value: Suspicion and trust in negotiation. Journal of Experimental Social Psychology, 46(3), 543-550. https://doi.org/10.1016/j.jesp.2009.11.002

Singh, J. (1988, January). Consumer complaint intentions and behavior: Definitional and taxonomical issues. Journal of Marketing, 52, 93-108. https://doi.org/10.2307/1251688

Singh, J., \& Wilkes, R.E. (1996). When consumers complain: A path analysis of the key antecedents of consumer complaint response estimates. Journal of the Academy of Marketing Science, 24(4), 350-365.

Svari, S., \& Olsen, L.E. (2012). The role of emotions in customer complaint behaviors. International Journal of Quality and Service Sciences, 4(3), 270-282. https://doi.org/10.1108/17566691211269585

Sweeney, J.C., Hausknecht, R., \& Soutar, G. (2000). Cognitive dissonance after purchase: A multidimensional scale. Psychology and Marketing, 17(5), 369-385.

Wang, E.S.T (2010). Internet usage purposes and gender differences in the effects of perceived utilitarian and hedonic value. Cyberpsychology, Behavior and Social Networking, 13(2), 179-183. https://doi.org/10.1089/cyber.2009.0200

Yap, S.F., \& Gaur, S.S. (2014). Consumer dissonance in the context of online consumer behavior: A review and research agenda. Journal of Internet Commerce, 13, 116-137. https://doi.org/10.1080/15332861.2014.934647

Zeelenberg, M., \& Pieters, R. (1999). Comparing service delivery to what might have been: Behavioral responses to regret and disappointment. Journal of Service Research, 2, 86-97. https://doi.org/10.1177/109467059921007

Zhang, K.Z.K., Cheung, C.M.K., \& Lee, M.K.O. (2012). Online service switching behavior: The case of blog service providers. Journal of Electronic Commerce Research, 13(3), 184-197. 